\title{
Sulfated Zirconia Modified SBA-15 Catalysts for Cellobiose Hydrolysis
}

\author{
Volkan Degirmenci - Deniz Uner • Basak Cinlar • \\ Brent H. Shanks • Aysen Yilmaz • Rutger A. van Santen • \\ Emiel J. M. Hensen
}

Received: 9 June 2010/Accepted: 12 October 2010/Published online: 26 October 2010

(C) The Author(s) 2010. This article is published with open access at Springerlink.com

\begin{abstract}
Zirconia modified SBA-15 becomes a very active catalyst for the selective hydrolysis of cellobiose to glucose after sulfation. Spectroscopic investigations indicate the presence of Brønsted acid sites with similar properties to those present in conventional sulfated zirconia. Indications are found that the sulfate groups attached to zirconia interact with silanol groups of SBA-15. The catalytic activity in cellobiose hydrolysis correlates well with results for temperature-programmed decomposition of $i$-propylamine for a range of sulfated $\mathrm{ZrO}_{2} / \mathrm{SBA}-15$ catalysts. A glucose yield of $60 \%$ during cellobiose hydrolysis at a reaction time of $90 \mathrm{~min}$ at $160{ }^{\circ} \mathrm{C}$ is obtained.
\end{abstract}

Keywords Sulfated zirconia $\cdot$ Mesoporous - SBA-15 · Cellobiose $\cdot$ Hydrolysis $\cdot$ Biomass

V. Degirmenci · D. Uner

Department of Chemical Engineering, Middle East Technical

University, 06531 Ankara, Turkey

B. Cinlar · B. H. Shanks

Department of Chemical and Biological Engineering, Iowa State University, Ames, IA 50011, USA

\footnotetext{
A. Yilmaz

Department of Chemistry, Middle East Technical University, 06531 Ankara, Turkey

V. Degirmenci ( $\square)$. R. A. van Santen · E. J. M. Hensen Schuit Institute of Catalysis, Eindhoven University of Technology, 5600 MB Eindhoven, The Netherlands e-mail: v.degirmenci@tue.nl
}

\section{Introduction}

So far, considerable effort has been dedicated for the economic production of ethanol as it is an excellent alternative transportation fuel and can be blended with gasoline $[1,2]$. However, ethanol is currently produced from sugar cane and the starch portion of corn, competing with food production, thus raising ethical concerns [3]. It is also very important to develop technologies for the efficient utilization of cellulose, a major constituent of lignocellulosic agricultural residues, as one of the renewable sources of chemicals $[4,5]$. Cellulose is a polymer of glucose monomers connected by $\beta$-1,4-glycosidic bonds. It can be hydrolyzed to glucose through enzymatic or acid hydrolysis $[6,7]$. The advantage of the enzymatic route is the absence of the degradation products but the reactions proceed rather slowly and separation is cumbersome [8]. Mineral acids can depolymerize cellulose into individual glucose units, accompanied by degradation products such as furfural, hydroxymethylfurfural and tar-like products. These side products are toxic for the microorganisms used for further fermentation of the glucose product. Recovery of the mineral acids is another challenge and in any case mineral acids are not desired because of their corrosive nature [9]. In order to overcome these drawbacks, heterogeneous catalytic systems have been proposed [10-17]. The conversion of cellulose into glucose and the simultaneous hydrogenation of glucose into sugar alcohols, such as sorbitol and mannitol on $\mathrm{Ru} / \mathrm{C}$ [11], polymer stabilized Ru nanoclusters [12], and $\mathrm{Pt}$ and $\mathrm{Ru}$ supported by HUSY and $\gamma-\mathrm{Al}_{2} \mathrm{O}_{3}$ [13] has been reported. In order to replace the mineral acids in the acid hydrolysis of cellulose, solid acid catalysts such as sulfonated activated carbon $\left(\mathrm{AC}-\mathrm{SO}_{3} \mathrm{H}\right)$ [14], sulfonic acidmesoporous materials $[15,16]$, and Brønsted acidic zeolites $[13,14]$ were used. Higher glucose yields were reported for 
sulfate modified catalysts than for acidic zeolites. Besides in the hydrolysis of sucrose and starch, sulfonated mesoporous silicas showed higher activities than ion exchange resins and HZSM-5 catalysts [17]. In this sense, sulfated zirconia is expected to show high glucose yields, albeit a significant amount of by-products has been noted [14].

The textural properties of conventional sulfated zirconia are not beneficial with relatively low surfaces areas (100-120 $\left.\mathrm{m}^{2} / \mathrm{g}\right)$. Much effort has been spent in order to prepare a high surface area sulfated zirconia. Mesoporous silicas have attracted wide-spread interest due to the high surface area (up to $1000 \mathrm{~m}^{2} / \mathrm{g}$ ), large pore volume, and a hexagonal array of uniform pores. The silanol groups on the surface of these materials are neutral or slightly acidic. Combining these beneficial textural properties of ordered mesoporous silicas with the intrinsic acidity of sulfated zirconia by dispersing the latter in the former would greatly enhance the catalytic activity. SBA- $n$ mesoporous materials $[18,19]$ have higher stability than other typical mesoporous silicas such as of the M41S family [20] due to their thicker walls, which should be beneficial when the aim is to introduce other components into the framework. The introduction of the zirconia precursor simultaneously with the silicon precursor in the preparation of SBA-15 was shown to be effective for a good distribution of zirconium within the silica framework [21].

In our previous work, we have found indications for strong Brønsted acidity of sulfate modified $\mathrm{ZrO}_{2} / \mathrm{SBA}-15$ by ${ }^{1} \mathrm{H}$ MAS NMR [22]. The origin of the strong surface acidity in sulfated zirconia has not been unequivocally resolved [23, 24]. Several postulates on the acidity, whether it is related to the sulfate group and various binding structures of this group to the zirconia surface, have been proposed [25-31]. Here, we investigated the surface acidity of a range of $\mathrm{ZrO}_{2} / \mathrm{SBA}$ 15 composites by infrared spectroscopy of adsorbed carbon monoxide. In addition, temperature-programmed decomposition of adsorbed alkylamines was used to probe the density of surface acidic sites. It is known that alkyl ammonium ions form upon protonation of amines by Brønsted sites and decompose into the corresponding alkene and $\mathrm{NH}_{3}$ in a narrow temperature range through a reaction similar to the Hoffman elimination [32]. The hydrolysis reactivity of a range of $\mathrm{ZrO}_{2} / \mathrm{SBA}-15$ composites was determined using cellobiose as a model substrate. Cellobiose is a dimer of glucose with $\beta$-1,4-glycosidic bonds, providing a useful model compound for the hydrolysis of cellulose.

\section{Experimental}

\subsection{Synthesis of Materials}

SBA-15 silica materials were prepared by a well-established procedure $[18,19]$. Siliceous SBA-15 was prepared by adding $9 \mathrm{ml}$ of tetraethyl orthosilicate (TEOS) to $150 \mathrm{ml}$ of $1.5 \mathrm{M} \mathrm{HCl}$ solution containing $4 \mathrm{~g}$ of Pluronic-123 (Aldrich). The mixture was stirred for $24 \mathrm{~h}$ at $40{ }^{\circ} \mathrm{C}$ and allowed to further react at $100{ }^{\circ} \mathrm{C}$ overnight in Teflon bottles. Subsequently, the solid material was obtained by filtration, dried at room temperature overnight and calcined at $500{ }^{\circ} \mathrm{C}$ in an air flow for $5 \mathrm{~h}$. Zirconium was introduced in the synthesis solution simultaneously with TEOS in the form of zirconiumoxychloride $\left(\mathrm{ZrOCl}_{2} \cdot 8 \mathrm{H}_{2} \mathrm{O}, 99.9 \%\right.$, Strem Chemicals). Appropriate amounts of the zirconium precursor were added to obtain final products with 5-25:100 $\mathrm{ZrO}_{2}: \mathrm{SiO}_{2}$ ratios. The materials are denoted as $\mathrm{Zr}(x) \mathrm{SBA}-$ 15 with $x$ being the $\mathrm{ZrO}_{2} \mathrm{M}$ amounts per 100 mol SiO 2 . Sulfated catalysts were prepared by sulfation in a $0.25 \mathrm{M}$ $\mathrm{H}_{2} \mathrm{SO}_{4}$ solution for $15 \mathrm{~min}$ followed by drying overnight at $80{ }^{\circ} \mathrm{C}$. The sulfated catalysts were activated at $350{ }^{\circ} \mathrm{C}$ for $3 \mathrm{~h}$ in static oven to remove the physisorbed sulfur species. Al-SBA-15 was prepared by prehydrolysing $0.25 \mathrm{~g}$ aluminum iso-propoxide (Acros Organics, 98\%) in $10 \mathrm{ml}$ of $\mathrm{HCl}$ solution. This solution was then added to the synthesis gel of SBA-15 to obtain Al-SBA-15. The Si/Al ratio is 34 in the final catalyst with a surface area of $903 \mathrm{~m}^{2} / \mathrm{g}$. Conventional sulfated zirconia was prepared by calcination of the sulfated zirconium hydroxide provided by MEL Chemicals (XZO $1249 / 01$ ) at $500{ }^{\circ} \mathrm{C}$ for $5 \mathrm{~h}$.

\subsection{Characterization}

Elemental analyses were carried out by ICP-OES (Spectro Ciros CCD ICP optical emission spectrometer with axial plasma viewing). To extract the metals, the catalysts were dissolved in a $1.5 \mathrm{ml}$ solution of $\mathrm{HF} / \mathrm{HNO}_{3} / \mathrm{H}_{2} \mathrm{O}(1: 1: 1)$ acid mixture.

TEM images were taken on a FEI T20 electron microscope operating at $200 \mathrm{kV}$. The specimens were dispersed in ethanol and placed on holey copper grids.

The surface areas were measured using nitrogen adsorption isotherms at $-196{ }^{\circ} \mathrm{C}$ on a Micromeritics ASAP 2000 gas sorption and porosimetry system. The samples were prepared for measurement by degassing at $150{ }^{\circ} \mathrm{C}$ for 24 h. Surface areas were calculated by the BET (BrunauerEmmett-Teller) method and the pore volumes were determined by using the BJH (Barrett-Joyner-Halenda) method by using the adsorption cumulative volume of pores between 1.7 and $100 \mathrm{~nm}$.

FT-IR spectra of the samples were recorded in the range of $4000-400 \mathrm{~cm}^{-1}$ by a Bruker IFS $113 \mathrm{v}$ instrument. The spectra were acquired at a $2 \mathrm{~cm}^{-1}$ resolution and averaged over 20 scans. The samples were prepared as thin selfsupporting wafers of $5-10 \mathrm{mg} / \mathrm{cm}^{2}$ and placed inside a controlled environment infrared transmission cell, capable of heating and cooling, gas dosing and evacuation. Prior to $\mathrm{CO}$ adsorption, the catalyst wafer was heated to $450{ }^{\circ} \mathrm{C}$ at a 
rate of $10{ }^{\circ} \mathrm{C} / \mathrm{min}$ in an oxygen atmosphere. Subsequently, the cell was out-gassed at the final temperature until the residual pressure was below $5 \times 10^{-5}$ mbar. The sample was then cooled to $-190{ }^{\circ} \mathrm{C}$. $\mathrm{CO}$ was introduced into the cell via a sample loop $(0.4 \mu \mathrm{mol}$ per dose $)$ connected to a Valco six-port valve.

Temperature programmed decomposition (TPD) of $i$-propylamine (IPAm) was performed in a packed-bed quartz reactor. The effluent gases were analyzed by a Balzers quadrupole mass spectrometer. $100 \mathrm{mg}$ of catalyst was heated at a rate of $5{ }^{\circ} \mathrm{C} / \mathrm{min}$ to $450{ }^{\circ} \mathrm{C}$ in a He flow of $100 \mathrm{ml} /$ min. The sample was then cooled to $100{ }^{\circ} \mathrm{C}$ and exposed to excess gaseous IPAm (99.5\%, Aldrich) for $10 \mathrm{~min}$. Physisorbed IPAm was removed at $100{ }^{\circ} \mathrm{C}$ by purging in $100 \mathrm{ml} /$ $\min \mathrm{He}$ for $24 \mathrm{~h}$. TPD of IPAm was carried out by heating the sample to $550{ }^{\circ} \mathrm{C}$ at a rate of $5{ }^{\circ} \mathrm{C} / \mathrm{min}$ in $200 \mathrm{ml} / \mathrm{min} \mathrm{He}$. The formation of propene $(\mathrm{m} / \mathrm{e}=41)$ and ammonia $(\mathrm{m} /$ $\mathrm{e}=17$ ), i.e. the decomposition products of IPAm, as well as the amount of desorbed IPAm (m/e $=44,41$, and 17) were followed and compared to well-calibrated standards. The TPD curves were carefully deconvoluted and the peak areas were used to determine the relative contributions.

\subsection{Catalytic Activity}

Cellobiose hydrolysis was carried out in a lab-scale batch reactor (Autoclave Engineers, $100 \mathrm{ml}$ ). Typically, the reactor was charged with a $50 \mathrm{ml}$ solution of $0.5 \mathrm{wt} \%$ cellobiose in water to which a predetermined amount of catalyst ( $0.1 \mathrm{wt} \%$ compared to solvent) was added. Kinetic experiments were performed at $160{ }^{\circ} \mathrm{C}$ under a nitrogen pressure of 20 bar. Nitrogen overpressure was employed to ensure that the reaction medium (water) remained as liquid during the reaction. The start of the reaction was taken as the moment when the reactor contents reached the desired reaction temperature. Although the reactors were heated as fast as possible, heating took about $10 \mathrm{~min}$, during which period some reaction already took place. When the loss of cellobiose was traced during heating, it was found that the loss was not more than $10 \%$ for each catalytic system under study amounting significantly lower than the initial rates. Samples were withdrawn every $30 \mathrm{~min}$ for $1.5 \mathrm{~h}$. Analysis was performed offline using a Waters HPLC system equipped with a $\mathrm{H}^{+}$-column (Polymer Lab.) and RI detector. The column temperature was kept constant at $60{ }^{\circ} \mathrm{C}$. The mobile phase was $10 \mathrm{mM}$ sulfuric acid solution which was fed at a flow rate of $0.6 \mathrm{ml} / \mathrm{min}$. The glucose and the cellobiose concentrations were determined from calibration curves prepared by using external standards.

The sulfur elution of the catalysts were determined at the reaction conditions as well. In a typical test, $10 \mathrm{mg}$ catalyst was added to $5 \mathrm{ml}$ of water for $0-60 \mathrm{~min}$ at $160{ }^{\circ} \mathrm{C}$. The catalyst was recovered by centrifugal separation under vacuum and the elemental analysis was performed by using a Perkin-Elmer Series II 2400 CHNS analyzer.

\section{Results and Discussion}

\subsection{Physicochemical Properties}

The intended compositions, $\mathrm{Zr}$ and $\mathrm{S}$ contents determined from the elemental analysis, $\mathrm{SO}_{4} / \mathrm{Zr}$ ratio and BET surface areas of the catalysts are collected in Table 1. Pure SBA-15 has a surface area of nearly $800 \mathrm{~m}^{2} / \mathrm{g}$, which is consistent

Table 1 Zirconia and sulfur contents of the catalysts determined by elemental analysis and the BET surface area of the non-sulfated and sulfated Zr-SBA-15

\begin{tabular}{|c|c|c|c|c|c|c|c|}
\hline \multirow[t]{2}{*}{ Catal } & \multicolumn{2}{|c|}{$\mathrm{Si} / \mathrm{Zr}$} & \multirow[t]{2}{*}{$\mathrm{Zr}(\mathrm{wt} \%)$} & \multirow[t]{2}{*}{$\mathrm{S}(\mathrm{wt} \%)$} & \multirow{2}{*}{$\begin{array}{l}\mathrm{SO}_{4} / \mathrm{Zr} \\
\text { molar ratio }\end{array}$} & \multirow{2}{*}{$\begin{array}{l}\text { BET surface } \\
\text { area }\left(\mathrm{m}^{2} / \mathrm{g}\right)\end{array}$} & \multirow{2}{*}{$\begin{array}{l}\text { Pore volume } \\
(\mathrm{cc} / \mathrm{g})\end{array}$} \\
\hline & Gel & Product & & & & & \\
\hline SBA-15 & $\mathrm{na}^{\mathrm{a}}$ & na & na & na & na & 773 & 1.18 \\
\hline $\mathrm{Zr}(15) \mathrm{SBA}-15$ & 7 & 26 & 5.3 & na & na & 586 & 1.46 \\
\hline $\operatorname{Zr}(25) S B A-15$ & 4 & 11 & 10.9 & na & na & 506 & 1.15 \\
\hline SZr(5)SBA-15 & 20 & 33 & 4.3 & 3.5 & 2.3 & 313 & 0.43 \\
\hline SZr(10)SBA-15 & 10 & 39 & 3.7 & 3.4 & 2.6 & 311 & 0.43 \\
\hline SZr(15)SBA-15 & 7 & 27 & 5.2 & 3.4 & 1.9 & 284 & 0.40 \\
\hline SZr(20)SBA-15 & 5 & 15 & 8.9 & 3.2 & 1.1 & 261 & 0.39 \\
\hline $\operatorname{SZr}(25) S B A-15$ & 4 & 12 & 10.8 & 3.3 & 0.9 & 246 & 0.34 \\
\hline SZr(30)SBA-15 & 3 & 13 & 13.4 & 3.1 & 0.7 & 203 & 0.24 \\
\hline SZ-Commercial & na & na & na & $7.0^{\mathrm{b}}$ & 0.22 & 123 & 0.10 \\
\hline Al-SBA-15 & na & na & na & na & na & 903 & 1.11 \\
\hline
\end{tabular}

\footnotetext{
a Not applicable

b Before calcination
} 


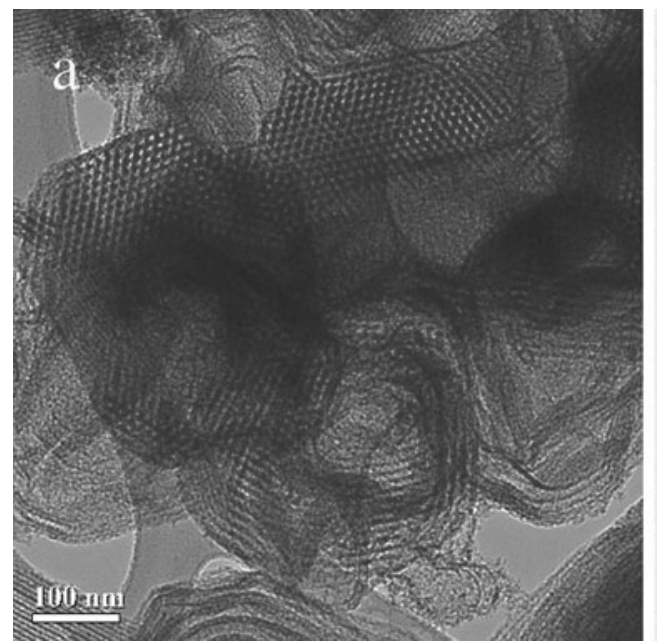

b

50) $\cdots \cdots 1$

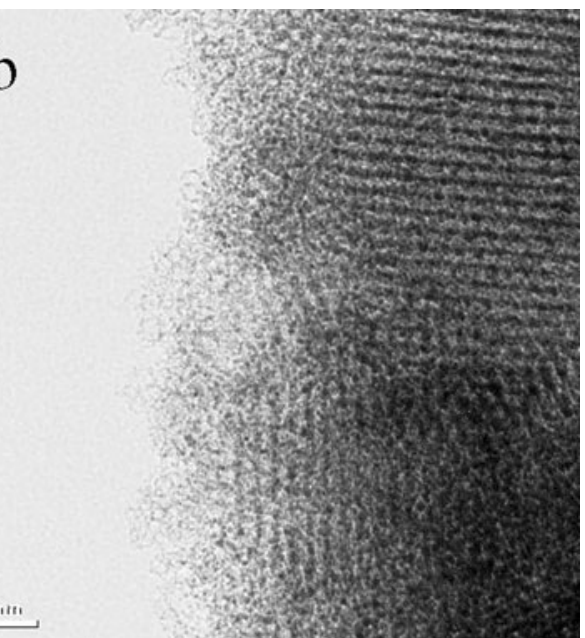

Fig. 1 Electron micrographs of a SBA-15 and b SZr(15)SBA-15

with the highly ordered mesostructure seen from TEM image (Fig. 1). Upon introduction of zirconia, the BET surface areas decreased to values between 500 and $600 \mathrm{~m}^{2} /$ $\mathrm{g}$, indicating that the introduction of zirconia in SBA-15 has resulted in a less ordered structure than siliceous SBA15. The zirconium contents in the calcined materials were lower than the amounts in the synthesis gel, implying that not all $\mathrm{Zr}$ was built into SBA-15 and remained dissolved in the synthesis solution. Initially, we used $1 \mathrm{M} \mathrm{H}_{2} \mathrm{SO}_{4}$ to sulfate the $\operatorname{Zr}(\mathrm{x}) \mathrm{SBA}-15$ materials, but this had a strong adverse effect on the textural properties (surface areas below $100 \mathrm{~m}^{2} / \mathrm{g}$ ). A sulfuric acid concentration of $0.25 \mathrm{M}$ was sufficient to provide good sulfation without causing too much loss of surface area. The surface area of the sulfated $\operatorname{Zr}(\mathrm{x})$ SBA- 15 materials was above $200 \mathrm{~m}^{2} / \mathrm{g}$ and still higher than that of conventional sulfated zirconia. The sulfur content of the calcined sulfated samples was about $3.3 \mathrm{wt} \%$ and did not change much with the $\mathrm{Zr}$ content. The $\mathrm{SO}_{4} / \mathrm{Zr}$ ratio decreases with $\mathrm{Zr}$ content. While this ratio is in excess of 2 at low $\mathrm{Zr}$ content, it decreases strongly above a $\mathrm{Zr}$ content of $5 \mathrm{wt} \%$. This may point to the gradual agglomeration of $\mathrm{Zr}$ ions into larger domains, of which only the outer surface can be sulfated. The XRD patterns did not show clear reflections in the low angle region for the zirconium-containing samples, indicating that the long range order of mesopores was absent. No reflections were observed in the high-angle region, implying that either the zirconium atoms were well dispersed or that the zirconia domains remain very small. Elemental analysis of the catalysts at various time under hydrothermal conditions at $160{ }^{\circ} \mathrm{C}$ (Table 2) indicated that a substantial part of the sulfur species are eluted under reaction conditions in the commercial sulfated zirconia catalyst as well as the SZr(x)SBA-15 catalysts.
Table 2 Sulfur contents of the catalysts after hydrothermal treatment at $160{ }^{\circ} \mathrm{C}$ determined by elemental analysis

\begin{tabular}{|c|c|c|c|c|}
\hline \multirow[t]{2}{*}{ Catalyst } & \multicolumn{4}{|l|}{$\mathrm{S}(\mathrm{wt} \%)$} \\
\hline & $0(\min )$ & $10(\min )$ & 30 (min) & $60(\min )$ \\
\hline SZr(15)SBA-15 & 3.40 & 0.30 & 0.20 & 0.20 \\
\hline $\operatorname{SZr}(25) S B A-15$ & 3.30 & 0.30 & 0.21 & 0.20 \\
\hline
\end{tabular}

\subsection{Infrared Spectroscopy of Adsorbed Carbon Monoxide}

A FT-IR spectrum in the CO stretching region of SBA-15 after carbon monoxide adsorption at liquid nitrogen temperature is shown in Fig. 2a. The spectra exhibit two distinct bands at 2138 and $2158 \mathrm{~cm}^{-1}$. The latter is attributed to $\mathrm{CO}$ adsorbed on weakly acidic silanol groups. The band at $2138 \mathrm{~cm}^{-1}$ is due to a weakly perturbed condensed carbon monoxide phase on the surface of SBA-15 [33, 34]. The weak feature at $2110 \mathrm{~cm}^{-1}$ derives from carbon monoxide coordinating with its oxygen atom to the silanol group. The FT-IR spectra in the CO stretching region of $\operatorname{Zr}(15)$ SBA-15 catalyst are given in Fig. 2b. In the presence of zirconia, an additional band at $2185 \mathrm{~cm}^{-1}$ was also observed. This band was assigned to Lewis acid sites formed by coordinatively unsaturated $\mathrm{Zr}^{4+}$ sites [32]. Increasing $\mathrm{CO}$ coverage saturated these sites earlier than the silanol groups, implying that the former sites bind $\mathrm{CO}$ stronger than the latter in accordance with the larger shift of the carbon monoxide stretching frequency.

Infrared spectra of $\mathrm{CO}$ adsorption on $\mathrm{SZr}(15) \mathrm{SBA}-15$ are shown in Fig. 2c. Similar to the non-sulfated catalyst, a band at $2138 \mathrm{~cm}^{-1}$ was observed due to the weakly physisorbed CO. The band around $2160 \mathrm{~cm}^{-1}$ was 

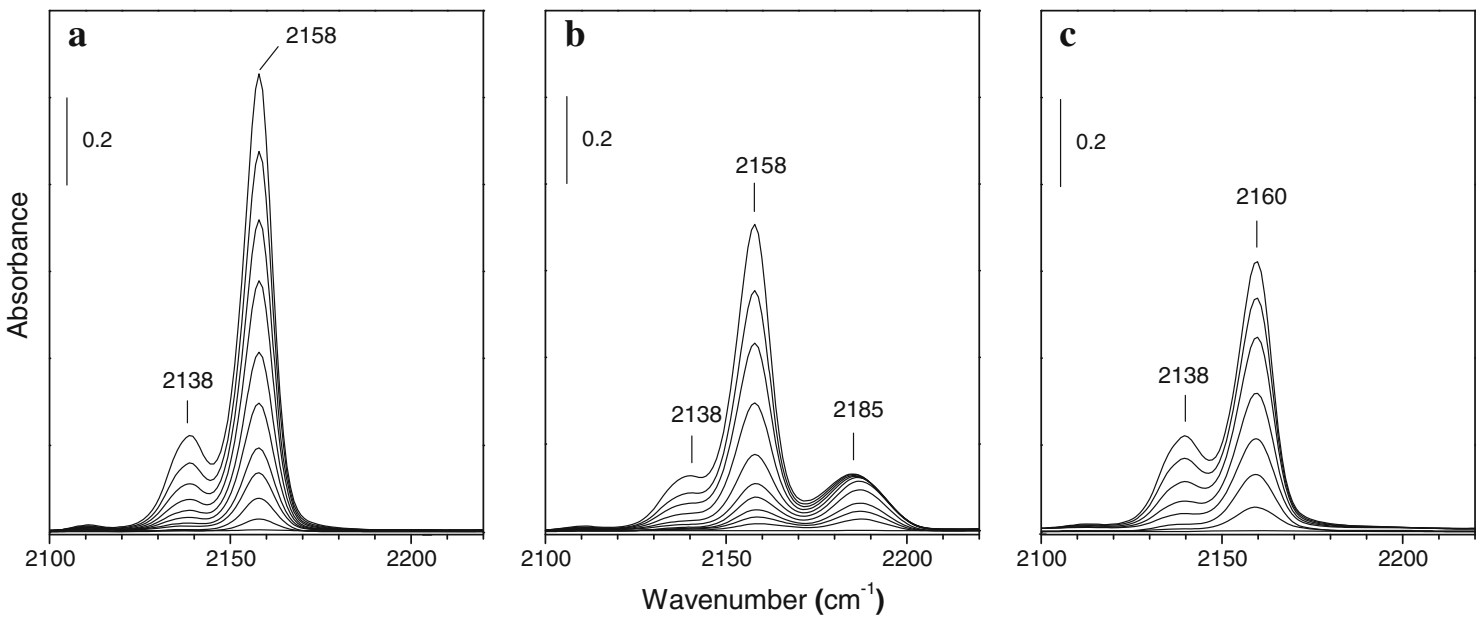

Fig. 2 FT-IR spectra of adsorbed carbon monoxide at liquid nitrogen temperature for a SBA-15, b Zr(15)SBA-15 and $\mathbf{c}$ SZr(15)SBA-15 upon increasing $\mathrm{CO}$ coverage (doses of $0.4 \mu \mathrm{mol} \mathrm{CO}$ )

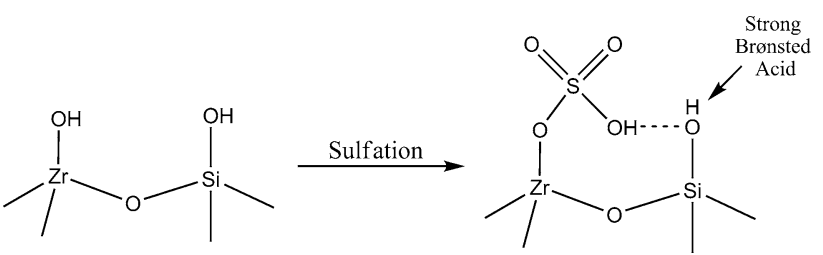

Scheme 1

attributed to $\mathrm{CO}$ adsorbed on silanol groups. It was located at a slightly higher wavenumber than that in SBA-15 and $\operatorname{Zr}(15)$ SBA-15 $\left(v_{\mathrm{CO}}=2158 \mathrm{~cm}^{-1}\right)$. The band at 2186 $\mathrm{cm}^{-1}$ due to $\mathrm{CO}$ coordinating to low coordinated $\mathrm{Zr}^{4+}$ sites disappeared on sulfated samples. This was attributed to complete coverage of the Lewis acid sites by sulfate groups. Scheme 1 gives a schematic representation of the low coordinated $\mathrm{Zr}^{4+}$ sites and silanol groups on the surface of the Zr-SBA-15 catalysts and the suggested formation of strong acid groups in the presence of sulfate groups for SZr-SBA-15 catalysts.

The infrared spectra of $\mathrm{CO}$ adsorption on conventional sulfated zirconia are shown in Fig. 3. The band at $2170 \mathrm{~cm}^{-1}$ was attributed to the $\mathrm{CO}$ adsorbed on terminal hydroxyl groups on the zirconia surface. The high frequency band was red-shifting with increasing $\mathrm{CO}$ coverage in the region between 2192 and $2205 \mathrm{~cm}^{-1}$. This band was assigned to the $\mathrm{C}-\mathrm{O}$ stretching mode of carbon monoxide interacting with Lewis acid sites, i.e. the $\mathrm{Zr}^{4+}$ sites, of varying acidity.

The infrared spectra in the silanol stretching region of SBA-15, $\operatorname{Zr}(15)$ SBA-15 and $\operatorname{SZr}(15)$ SBA-15 catalysts are shown in Fig. 4a-c, respectively. The spectrum of SBA-15 (Fig. 4a) exhibits a sharp feature at $3747 \mathrm{~cm}^{-1}$ which is ascribed to the isolated, non-hydrogen bonded silanol groups on the surface. The broad tail extending towards $3400 \mathrm{~cm}^{-1}$ is due to the hydrogen bonded silanol groups.

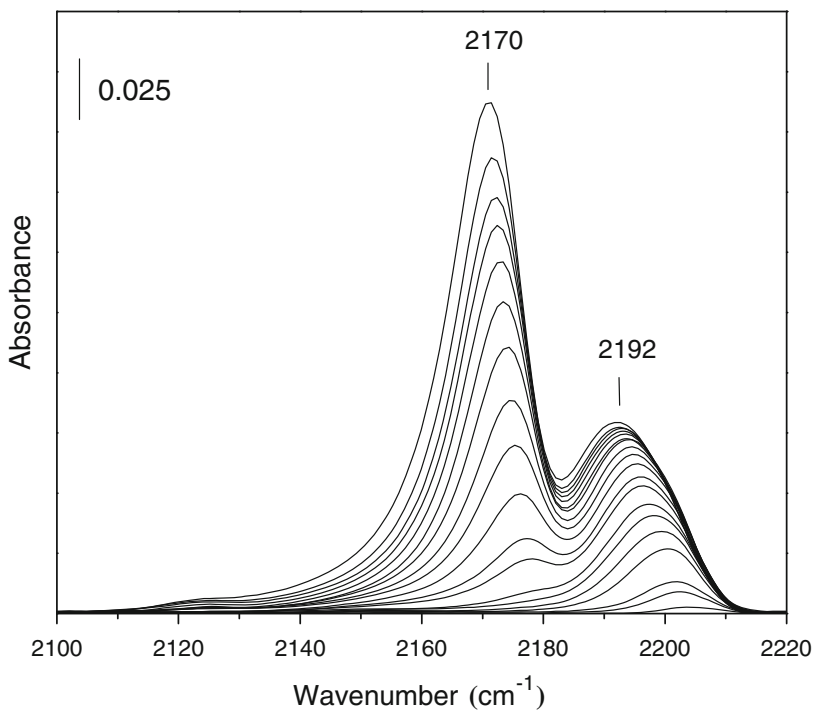

Fig. 3 FT-IR spectra of adsorbed carbon monoxide at liquid nitrogen temperature for commercial sulfated zirconia upon increasing $\mathrm{CO}$ coverage (doses of $0.4 \mu \mathrm{mol} \mathrm{CO}$ )

$\mathrm{CO}$ adsorption on isolated silanol groups weakens the hydroxyl bond and leads to a perturbed band around $3653 \mathrm{~cm}^{-1}$ with a frequency shift of $94 \mathrm{~cm}^{-1}$. The silanol stretching region of the $\mathrm{Zr}(15) \mathrm{SBA}-15$ catalyst (Fig. $4 \mathrm{~b}$ ) is similar to pure SBA-15 with the exception of a very weak feature around $3794 \mathrm{~cm}^{-1}$ attributed to isolated terminal hydroxyl groups bonded to $\mathrm{Zr}$. The shift of the hydroxyl groups upon CO adsorption is very similar to SBA-15. This indicates the silanol groups are still only weakly acidic in the zirconia-substituted SBA-15.

The corresponding hydroxyl region for $\mathrm{SZr}(15)$ SBA-15 is shown in Fig. 4c. The intensity of the band at $3747 \mathrm{~cm}^{-1}$ is less pronounced than the intensity of the corresponding bands on SBA-15 or Zr/SBA-15 samples. The IR spectra as 
Fig. 4 FT-IR spectra of adsorbed carbon monoxide at liquid nitrogen temperature in the hydroxyl stretching region for a SBA-15, b $\mathrm{Zr}(15)$ SBA-15 and $\mathbf{c} \operatorname{SZr}(15)$ SBA-15 upon increasing $\mathrm{CO}$ coverage (doses of $0.4 \mu \mathrm{mol} \mathrm{CO}$ ). The red line represents the spectra before the addition of $\mathrm{CO}$. The arrow indicates the increasing $\mathrm{CO}$ coverage

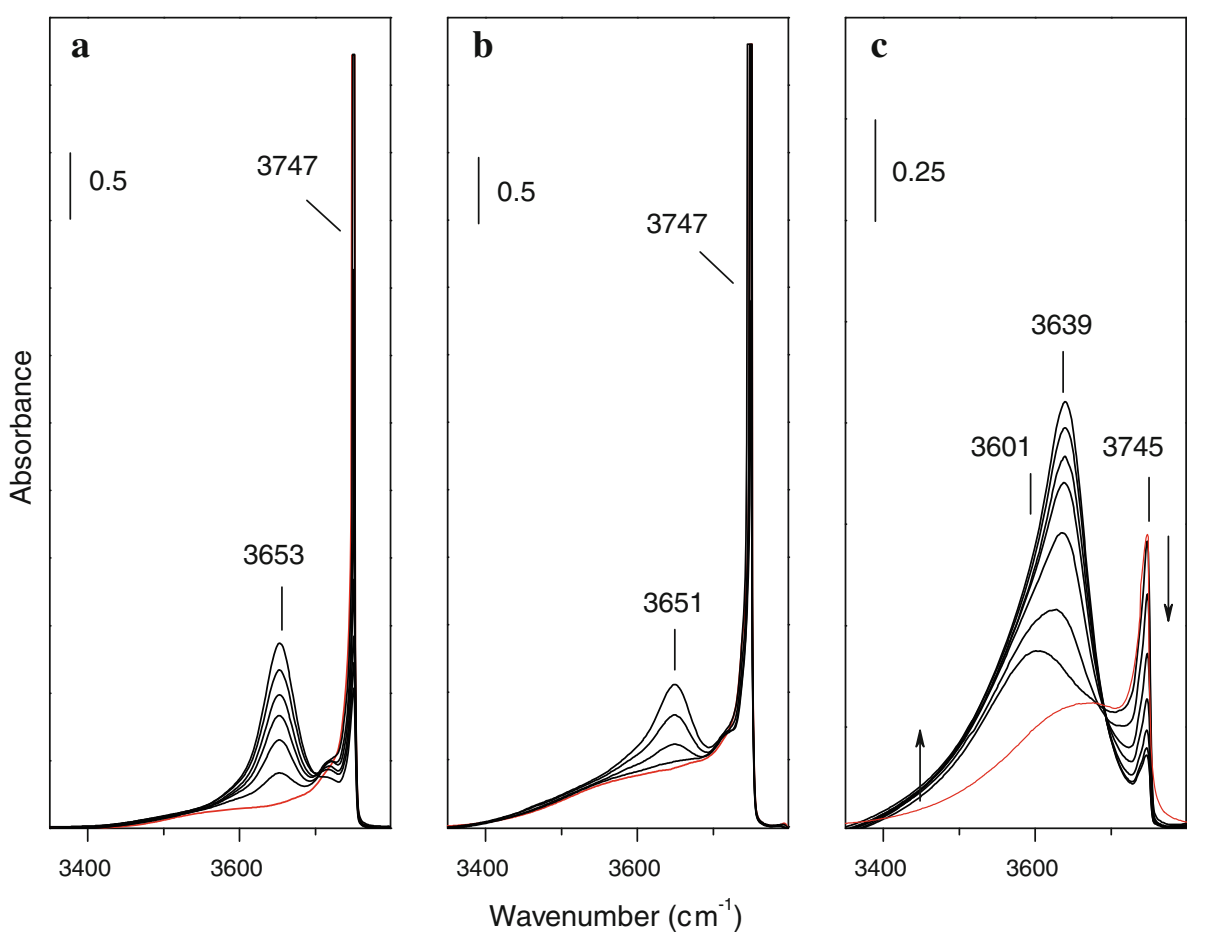

a function of $\mathrm{CO}$ coverage clearly evidence the presence of two types of silanol groups. At low $\mathrm{CO}$ coverage, part of the hydroxyl band at $3745 \mathrm{~cm}^{-1}$ is shifted to $3601 \mathrm{~cm}^{-1}$, corresponding to a shift of $144 \mathrm{~cm}^{-1}$. With increasing $\mathrm{CO}$ coverage, the band of perturbed $\mathrm{OH}$ broadens and $\Delta v_{\mathrm{OH}}$ at high $\mathrm{CO}$ coverage is $106 \mathrm{~cm}^{-1}$. The evolution of the spectra evidence the presence of stronger acidic sites giving rise to $\Delta v_{\mathrm{OH}}=144 \mathrm{~cm}^{-1}$ next to weakly acidic sites $\left(\Delta v_{\mathrm{OH}}=94 \mathrm{~cm}^{-1}\right)$. An IR frequency shift of $144 \mathrm{~cm}^{-1}$ upon $\mathrm{CO}$ adsorption on $\mathrm{SZr}(15) \mathrm{SBA}-15$ is very close to the $139 \mathrm{~cm}^{-1}$ shift reported earlier for a conventional sulfated zirconia catalyst [35].

Previous FT-IR investigations provide evidence that sulfation of zirconia enhances the strength of the bridging zirconia hydroxyl groups, that is $\mathrm{Zr}-(\mathrm{OH})-\mathrm{Zr}$, and eliminates the terminal ones (i.e., $\mathrm{ZrOH}$ ) [27]. In addition, it creates a new type of Brønsted acid site, presumably protons forming multicentered or single bonds with sulfate ions. These protons are hydrogen bonded to the surface [28]. Similarly, when zirconia included SBA-15 was modified by sulfation, the Lewis acid sites were covered by sulfate groups and the terminal hydroxyls of zirconia were eliminated (Fig. 5). As a result of the interaction of these sulfate ions with the silanol groups, strong Brønsted acidity is developed.

The presence of strong Brønsted acidity was indicated by the sulfate and the silanol stretching regions. The red shift $\left(\Delta v_{\mathrm{OH}}=144 \mathrm{~cm}^{-1}\right)$ observed in the silanol stretching region for SZr-SBA-15 catalysts upon $\mathrm{CO}$ adsorption is similar to that for conventional sulfated zirconia reported in literature $\left(\Delta v_{\mathrm{OH}}=139 \mathrm{~cm}^{-1}\right)$ [35]. This suggests that our catalysts have similar acidity as conventional sulfated zirconia. The $\Delta v_{\mathrm{OH}}$ of $144 \mathrm{~cm}^{-1}$ is higher than the shift for weakly acidic silanol, yet lower than that of strongly acidic zeolites (stabilized faujasite zeolite, $\Delta v_{\mathrm{OH}} \approx 300 \mathrm{~cm}^{-1}$ ) [36, 37]. The IR spectra of the $\mathrm{S}=\mathrm{O}$ stretching region for $\mathrm{SZr}(15)$ SBA-15 are presented in Fig. 6. CO adsorption brings about a positive frequency shift of about $26 \mathrm{~cm}^{-1}$. This shift indicates an increase of the $\mathrm{S}=\mathrm{O}$ bond strength and is attributed to the interaction of $\mathrm{CO}$ with the strongly acidic proton, as weakening of the $\mathrm{SO}-\mathrm{H}$ bond upon interaction of the proton with $\mathrm{CO}$ causes an increase of the $\mathrm{S}=\mathrm{O}$ bond strength. This observation provides an indirect indication for the presence of protonic sites connected to the sulfate groups. Indeed, direct observation of the strong Brønsted acid protons in sulfated zirconia catalysts is not straightforward, likely because of the strong hydrogen bonding to adjacent surface groups [22].

\subsection{Temperature-Programmed Decomposition of IPAm}

The evolution of propene during temperature programmed IPAm decomposition for the various catalysts is shown in Fig. 7. No IPAm decomposition is observed for siliceous SBA-15. For the zirconia-containing catalysts, decomposition of adsorbed IPAm takes place between 310 and $360{ }^{\circ} \mathrm{C}$ with a maximum around $340{ }^{\circ} \mathrm{C}$. In contrast, the decomposition in the sulfated catalysts occurred in the interval $290-340{ }^{\circ} \mathrm{C}$ with a maximum around $312{ }^{\circ} \mathrm{C}$. In Table 3, the amounts of decomposed IPAm as well as the 
Fig. 5 FT-IR spectra of adsorbed carbon monoxide at liquid nitrogen temperature in $\mathrm{ZrOH}$ stretching region for a non sulfated $\mathrm{Zr}(25) \mathrm{SBA}-15$ and $\mathbf{b}$ sulfated $\mathrm{Zr}(25)$ SBA-15 upon increasing $\mathrm{CO}$ coverage (doses of $0.4 \mu \mathrm{mol} \mathrm{CO}$ )

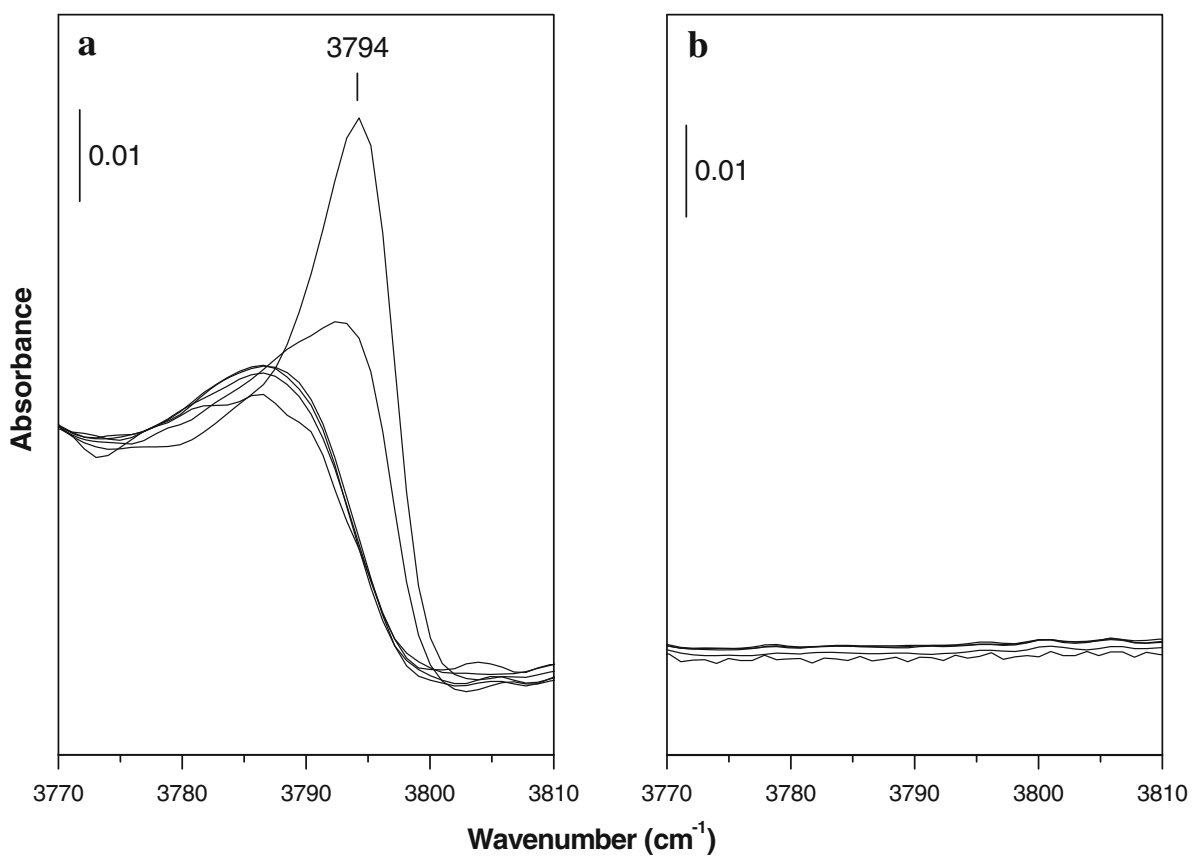

Upon sulfation, the decomposition temperature for $\operatorname{Zr}(15) \mathrm{SBA}-15$ decreases considerably. The difference is due to the increased acidity of the catalysts. This leads to activation of the chemisorbed IPAm complex at lower temperature. Table 3 also gives the results for two reference samples HZSM-5 and Al-SBA-15. The former contains exclusively aluminum in the zeolite framework and the amount of IPAm decomposed corresponds to the aluminum density. The latter contains mainly Lewis acidic $\mathrm{Al}$ sites on the surface of SBA-15. IPAm chemisorbed to these Lewis acidic sites decomposes at a higher temperature and the result is very similar to that of the non-sulfated $\operatorname{Zr}(x) /$ SBA-15 samples. It is then straightforward to conclude that IPAm in the non-sulfated catalyst adsorbs to Lewis acid $\mathrm{Zr}^{4+}$ sites, whereas this adsorption state should be absent after sulfation. Instead, the Brønsted acidic sites adsorb IPAm more strongly through protonation of the alkylamine, which results in a lower decomposition temperature. For the series of sulfated $\operatorname{Zr}(x) / \mathrm{SBA}-15$, the amount of decomposed IPAm first increases up to a value of $0.5 \mathrm{mmol} / \mathrm{g}$ for $\mathrm{SZr}(15) \mathrm{SBA}-15$ and then decreases with increasing $\mathrm{Zr}$ content. The increase of the acidity at lower $\mathrm{Zr}$ content indicates the increase of the number of $\mathrm{Zr}$ ions in or at the SBA-15 surface and points to their dispersed nature. At higher $\mathrm{Zr}$ content, zirconia domains are formed, which have a lower number of $\mathrm{Zr}$ ions at their surface. This is in line with the lower $\mathrm{SO}_{4} / \mathrm{Zr}$ ratios. In principle, the decrease of the acidity with increasing $\mathrm{Zr}$ content may thus be due to the formation of segregated domains of zirconia. An additional reason may lie in the importance of the interaction of sulfate groups attached to $\mathrm{Zr}$ ions with silanol groups in acidity generation as indicated by the IR results. decomposition temperature are given for these catalysts. Introduction of zirconia in the silica results in the creation of sites capable of chemisorbing and decomposing IPAm. 


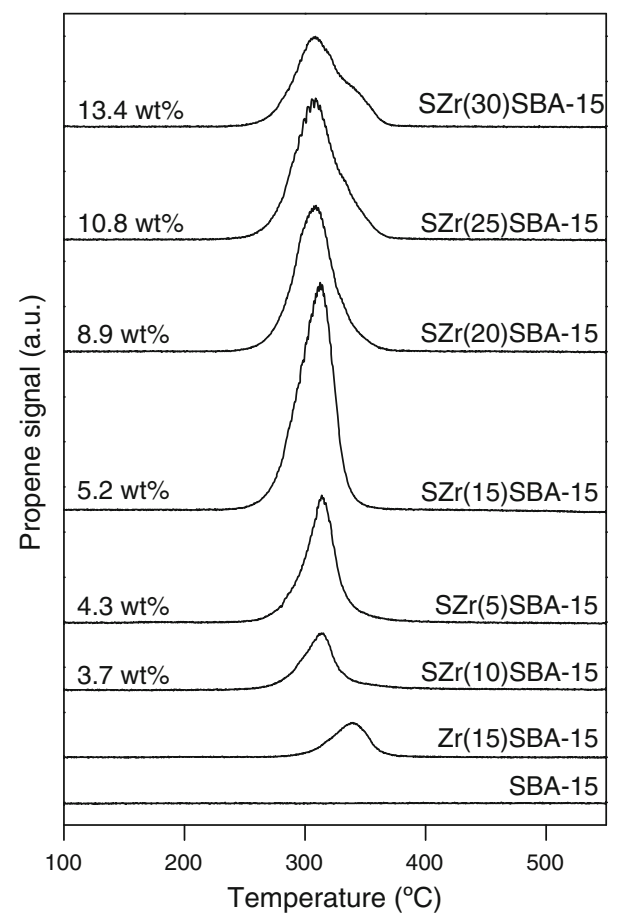

Fig. 7 Production of propene from $i$-propylamine decomposition during TPD for the various catalysts. Actual $\mathrm{Zr}$ loadings determined by elemental analysis for zirconium-containing silicas are indicated left

Obviously, agglomeration of $\mathrm{Zr}$ at the surface of SBA-15 surface results in a decrease of the interaction of the grafted sulfate with the silanol groups and may thus decrease overall acidity. For SZr(20)SBA-15 and the samples with higher $\mathrm{Zr}$ loading, we find that there are two peaks in propene production, one main peak around $310{ }^{\circ} \mathrm{C}$ and the other smaller contribution around $340{ }^{\circ} \mathrm{C}$. The contribution of the latter peak increases somewhat with the zirconium loading. As its location is similar to the peak observed for the non-sulfated sample, we infer that these samples contain a small amount of Lewis acidic $\mathrm{Zr}^{4+}$ sites.

\subsection{Catalytic Activity}

The conversion of cellobiose and the yield to glucose at a reaction temperature at $160{ }^{\circ} \mathrm{C}$ are given in Fig. 8. Comparing the SBA- 15 based catalysts; the sulfated catalysts are more active in cellobiose conversion. The cellobiose conversion is about $80 \%$ after 90 min for $\mathrm{SZr}(15) \mathrm{SBA}-15$ and $\mathrm{SZr}(25)$ SBA-15. In comparison, $\mathrm{Zr}(15)$ SBA-15 displays a much lower activity. The activity of an Al-SBA- 15 reference catalyst is also very low. The lower activities of $\mathrm{Zr}(15) \mathrm{SBA}$ 15 imply that the hydrolysis of cellobiose is more favorable on Brønsted acid sites than on Lewis acid sites. The activity of the conventional sulfated zirconia material is very close to the sulfated $\operatorname{Zr}(x)$ SBA- 15 materials. On the other hand, the glucose yields of the sulfated $\operatorname{Zr}(x)$ SBA- 15 are much higher than conventional sulfated zirconia. Catalysts with Brønsted acid sites showed high selectivity for glucose in previous studies $[16,38]$. Hence, the higher yields of glucose on sulfated $\operatorname{Zr}(x)$ SBA-15 in comparison to conventional sulfated zirconia is most likely due to the small amount of Lewis acid sites, known to catalyze the dehydration of glucose. The hydrolysis reactions are generally followed by glucose degradation reactions, including condensation, fragmentation and resinification reactions producing polyacids, sugar derivatives and polymeric residues [14]. Therefore, we limit ourselves here to follow cellobiose conversion and glucose yield.

The sulfur content of all the catalysts decreased under reaction conditions. A comparison of the two composite catalysts $\operatorname{SZr}(15)$ SBA-15 and $\mathrm{SZr}(25) \mathrm{SBA}-15$ shows that the sulfur contents during catalytic operation are very similar (Table 2). The $\mathrm{SZr}(15) \mathrm{SBA}-15$ catalyst is more active and this is undoubtedly related to the higher amount of Brønsted acid sites. Our IPAm decomposition results show that the $\operatorname{SZr}(15)$ SBA-15 catalyst has the highest Brønsted acidity content. The incorporation of sulfated zirconia into SBA-15 structure does not substantially improve hydrothermal stability as sulfur species leach during reaction.
Table 3 IPAm decomposition temperatures and amounts for different catalysts a $\mathrm{Si} / \mathrm{Al}=20$

b $\mathrm{Si} / \mathrm{Al}=34$

\begin{tabular}{|c|c|c|c|c|c|c|}
\hline Catalyst & $\begin{array}{l}\text { Zr loading } \\
\text { (wt } \% \text { ) }\end{array}$ & $\begin{array}{l}N_{\text {IPAm, total }} \\
\text { (mmol/g cat.) }\end{array}$ & $\begin{array}{l}T_{\max , 1} \\
\left({ }^{\circ} \mathrm{C}\right)\end{array}$ & $\begin{array}{l}N_{\text {IPAm, } 1} \\
\text { (mmol/g cat.) }\end{array}$ & $\begin{array}{l}T_{\max , 2} \\
\left({ }^{\circ} \mathrm{C}\right)\end{array}$ & $\begin{array}{l}N_{\text {IPAm, } 2} \\
\text { (mmol/g cat.) }\end{array}$ \\
\hline SBA-15 & - & 0.0 & - & - & - & - \\
\hline $\mathrm{Zr}(15) \mathrm{SBA}-15$ & 5.3 & 0.09 & - & - & 340 & 0.09 \\
\hline SZr(5)SBA-15 & 4.3 & 0.26 & 314 & 0.26 & - & - \\
\hline SZr(10)SBA-15 & 3.7 & 0.14 & 313 & 0.14 & - & - \\
\hline SZr(15)SBA-15 & 5.2 & 0.50 & 313 & 0.50 & - & - \\
\hline $\operatorname{SZr}(20)$ SBA-15 & 8.9 & 0.37 & 307 & 0.36 & 342 & 0.01 \\
\hline $\operatorname{SZr}(25) S B A-15$ & 10.8 & 0.39 & 308 & 0.36 & 341 & 0.03 \\
\hline SZr(30)SBA-15 & 13.4 & 0.27 & 308 & 0.23 & 342 & 0.04 \\
\hline HZSM- $5^{\mathrm{a}}$ & - & 0.82 & 310 & 0.82 & - & - \\
\hline Al-SBA- $15^{\mathrm{b}}$ & - & 0.09 & 345 & 0.09 & - & - \\
\hline
\end{tabular}



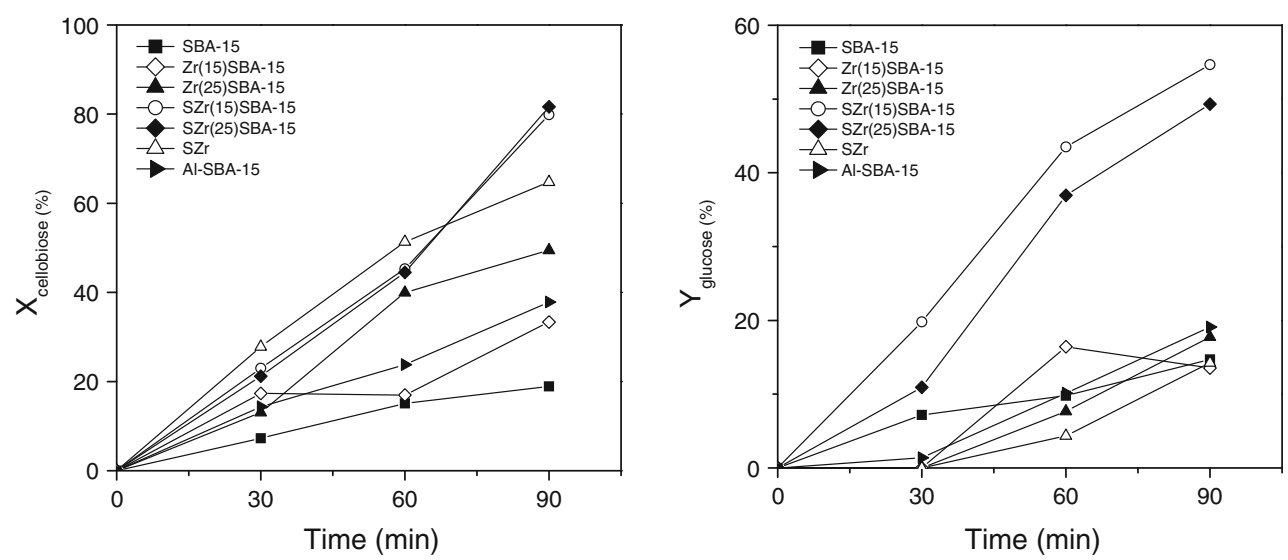

Fig. 8 Cellobiose conversion (left) and glucose yield (right) as a function of reaction time for a large set of catalysts $\left(T=160{ }^{\circ} \mathrm{C} ; p_{\mathrm{N} 2}=30 \mathrm{bar}\right.$; autoclave; $0.5 \mathrm{wt} \%$ cellobiose and $0.1 \mathrm{wt} \%$ catalyst in water)

\section{Conclusions}

Strong Brønsted acidity of sulfated zirconia-SBA-15 catalysts was demonstrated by FTIR spectroscopy of surface hydroxyls upon CO adsorption and TPD of IPAm decomposition. The strong acidity of these materials results from the sulfation of zirconia patches of varying dispersion included in or at the surface of SBA-15. The acidity before sulfation stems from Lewis acidic $\mathrm{Zr}^{4+}$ sites. The higher intrinsic Brønsted acidity of a sulfated zirconia modified SBA-15 is close to that of conventional sulfated zirconia. IR spectroscopy suggests that the Brønsted acidity derives from interactions between sulfate groups attached to zirconia and silanol groups. An optimum in the acidity with respect to $\mathrm{Zr}$ content is observed. Sulfated zirconia dispersed throughout SBA-15 is an active catalyst for the scission of the 1,4- $\beta$ glycosidic bonds in cellobiose, which is a model reaction for the critical step in the depolymerization of cellulose into valuable chemicals. The present study suggests that the isolated Brønsted acid sites catalyze cellobiose hydrolysis resulting in high glucose yields.

Acknowledgments VD is grateful for the doctoral scholarship and exchange grants from the Scientific and Research Council of Turkey (TUBITAK) through the BDP program. National Science Foundation supported this work through grant CTS-0455965. This work has been partially supported by Dutch Technology Foundation (STW) under a VIDI grant. We thank the MEL Chemicals for providing the sulfated zirconium hydroxide. We would like to acknowledge Jie Fan and Galen Stucky (UC, Santa Barbara) for transmission electron microscopy measurements.

Open Access This article is distributed under the terms of the Creative Commons Attribution Noncommercial License which permits any noncommercial use, distribution, and reproduction in any medium, provided the original author(s) and source are credited.

\section{References}

1. Farrell AE, Plevin RJ, Turner BT, Jones AD, O'Hare M, Kammen DM (2006) Science 311:506

2. Lynd LR, Cushman JH, Nichols RJ, Wyman CE (1991) Science 251:1318

3. Service RF (2007) Science $315: 1488$

4. Huber GW, Iborra S, Corma A (2006) Chem Rev 106:4044

5. Ragauskas AJ, Williams CK, Davison BH, Britovsek G, Cairney J, Eckert CA, Frederick WJ, Hallett JP, Leak DJ, Liotta CL, Mielenz JR, Murphy R, Templer R, Tschaplinski T (2006) Science 311:484

6. Zhang YHP, Lynd LR (2004) Biotechnol Bioeng 88:797

7. Mok WSL, Antal MJ, Varhegyi G (1992) Ind Eng Chem Res 31:94

8. Saha BC, Bothast RJ (1999) Appl Biochem Biotechnol 76:65

9. Wyman CE (1994) Bioresour Technol 50:3

10. Takagaki A, Tagusagawa C, Hayashi S, Harad M, Domen K (2010) Energ Environ Sci 3:82

11. Luo C, Wang SA, Liu HC (2007) Angew Chem Int Ed 46:7636

12. Yan N, Zhao C, Luo C, Dyson PJ, Liu HC, Kou Y (2006) J Am Chem Soc 128:8714

13. Fukuoka A, Dhepe PL (2006) Angew Chem Int Ed 45:5161

14. Onda A, Ochi T, Yanagisawa K (2008) Green Chem 10:1033

15. Nakajima K, Okamura M, Kondo JN, Domen K, Tatsumi T, Hayashi S, Hara M (2009) Chem Mater 21:186

16. Bootsma JA, Shanks BH (2007) Appl Catal A Gen 327:44

17. Dhepe PL, Ohashi M, Inagaki S, Ichikawa M, Fukuoka A (2005) Catal Lett 102:163

18. Zhao DY, Huo QS, Feng JL, Chmelka BF, Stucky GD (1998) J Am Chem Soc 120:6024

19. Zhao DY, Feng JL, Huo QS, Melosh N, Fredrickson GH, Chmelka BF, Stucky GD (1998) Science 279:548

20. Beck JS, Vartuli JC, Roth WJ, Leonowicz ME, Kresge CT, Schmitt KD, Chu CTW, Olson DH, Sheppard EW, McCullen SB, Higgins JB, Schlenker JL (1992) J Am Chem Soc 114:10834

21. Du YC, Sun YY, Di Y, Zhao L, Liu S, Xiao FS (2006) J Porous Mater 13:163

22. Degirmenci V, Erdem OF, Yilmaz A, Michel D, Uner D (2007) Catal Lett 115:79

23. Song XM, Sayari A (1996) Cat Rev Sci Eng 38:329

24. Kanougi T, Atoguchi T, Yao S (2002) J Mol Catal A Chem 177:289 
25. Bensitel M, Saur O, Lavalley JC, Morrow BA (1988) Mater Chem Phys 19:147

26. Clearfield A, Serrette GPD, Khazisyed AH (1994) Catal Today 20:295

27. Riemer T, Spielbauer D, Hunger M, Mekhemer GAH, Knozinger H (1994) J Chem Soc Chem Commun 10:1181

28. Kustov LM, Kazansky VB, Figueras F, Tichit D (1994) J Catal $150: 143$

29. Adeeva V, Dehaan JW, Janchen J, Lei GD, Schunemann V, Vandeven LJM, Sachtler WMH, van Santen RA (1995) J Catal 151:364

30. Li XB, Nagaoka K, Lercher JA (2004) J Catal 227:130

31. Olindo R, Li XB, Lercher JA (2006) Chem Ing Tech 78:1053
32. Palkhiwala AG, Gorte RJ (1999) Catal Lett 57:19

33. Beebe TP, Gelin P, Yates JT (1984) Surf Sci 148:526

34. Hadjiivanov K, Reddy BM, Knozinger H (1999) Appl Catal A Gen 188:355

35. Manoilova OV, Olindo R, Arean CO, Lercher JA (2007) Catal Commun 8:865

36. Crepeau G, Montouillout V, Vimont A, Mariey L, Cseri T, Mauge F (2006) J Phys Chem B 110:15172

37. Morterra C, Cerrato G, Bolis V, DiCiero S, Signoretto M (1997) J Chem Soc Faraday Trans 93:1179

38. Shimizu K, Furukawa H, Kobayashi N, Itaya Y, Satsuma A (2009) Green Chem 11:1627 